ISSN: 2362-1303 (Paper) | eISSN: 2362-1311 (Online)

JOURNAL OF ADVANCED ACADEMIC RESEARCH (JAAR)

June 2021

\title{
Depression, Stress and Anxiety among Residents of Nepal during COVID-19 Lockdown
}

\section{Sandhya Basnet ${ }^{1}$, Bhawana Bhandari ${ }^{2}$, Bipula Gaire ${ }^{3}$, Pujan Sharma ${ }^{4}$ and Rajendra Man Shrestha $^{5}$}

${ }^{1}$ Nursing Lecturer, Hope International College, Lalitpur, Nepal

${ }^{2}$ Nursing Lecturer, Hope International College, Lalitpur, Nepal

${ }^{3}$ Nursing Lecturer, Manipal College of Medical Sciences, Pokhara, Nepal

${ }^{4}$ Psychologist, Manmohan Memorial College and Teaching Hospital, Kathmandu, Nepal

${ }^{5}$ Associate Professor, Padmakanya Multiple Campus, Kathmandu, Nepal

\section{Corresponding Author}

Sandhya Basnet

Email: sandhyabasnetkc123@gmail.com

\begin{abstract}
Covid-19 illness is a pandemic infectious disease caused by a new coronavirus that originated in Wuhan, China. Nepal being a landlocked underdeveloped country is particularly vulnerable to the pandemic. Similarly, the dread of contracting the coronavirus is making people concerned about a global pandemic. It is vital to determine the impact of viral outbursts on mental health. Hence, this study aims to identify level of depression, stress and anxiety during lockdown among Nepalese residents. Cross-section web-based research design was undertaken at Bagmati province, Gandaki province and Lumbini province with four hundred twenty-two $(n=422)$ $(n=422)$ Nepalese residents by using a multistage proportionate stratified random sampling method. The Dass-21 tool was used to assess level of depression, stress and anxiety. Among 422 respondents only $5.9 \%$ had extremely severe level of anxiety, whereas $14.5 \%$ were moderately depressed, $77.5 \%$ did not have any stress during lockdown. There was statistically significant difference between depression and age $(\mathrm{p}=0.016)$, depression and sex $(\mathrm{p}=0.023)$. Also, there was a significant difference between stress and age $(\mathrm{p}=0.023)$, sex $(\mathrm{p}=0.0263)$ and education level $(\mathrm{p}=0.049)$.It is concluded that more than two-third of the respondents were found to be in normal ranges for depression, stress and anxiety. Less than one-fourth of respondents had moderate to severe level of anxiety and depression.
\end{abstract}

\section{KEYWORDS}

Anxiety, Covid-19, Depression, Lockdown, Nepalese Residents, Stress 


\section{INTRODUCTION}

According to United Nations International Children's Education Fund (2020), originally started in Wuhan, China, Covid-19 disease is a newly discovered pandemic infectious disease caused by novel coronavirus. According to the World Health Organization, globally 8,844,171 cases are infected from Covid-19. As for Nepal, on June 22, 2020, 9026 cases have been confirmed with 23 deaths. Depression is a prevalent mental disorder that affects over 264 million individuals worldwide and is marked by continuous sadness and a loss of interest in formerly rewarding or enjoyable activities. In developing countries, $76-85 \%$ of people suffering from mental illnesses do not have access to the therapy they require (United Nations Development Program, 2020). Several studies conducted in China, first affected country from Covid-19 shows that fear of getting infected and strict lockdown measures led to several mental consequences such as depression, stress and anxiety. According to the evidence, symptoms of anxiety and depression (16-28\%) and self-reported stress (8\%) are common psychological reactions to the COVID-19 pandemic (Rajkumar, 2020). As reports of United Nations International Children's Emergency Fund (2020), given the country's previously high suicide rates, the pandemic has aggravated the problem. Since mid-March 2020, 1,350 people have died by suicide, which was overwhelmed by the emotional and mental toll of months of uncertainty, which was sometimes worsened by trauma and losses. With the prolonged period of lockdown, people are suffering from fear and stress of getting infected, on the other hand, people are suffering from financial crisis, hunger, unfacilitated quarantine stay, boredom due to never ending lockdown (Asmundson \& Taylor, 2020).As a result of rapidly spreading global pandemic general population were experiencing increased level of stress and anxiety. Residents are confined to their homes as a result of the lockdown, which has negative mental health consequences such as anxiety and uncertainty about the future. The impact of such occurrences on mental health can occur immediately afterwards and then last for a long time. (Brooks et.al., 2020). A recent study conducted in Kashmir showed that $67.5 \%$ of the general population had psychological problem among the new problems faced after lockdown (Bhat et.al., 2020). Similar study in China revealed that almost $35 \%$ of the respondents experienced psychological distress during the lockdown (Dong \& Bouey, 2020). The sparse literature on the mental health consequences of outbreaks relates more to the sequelae of the disease itself than to social distancing and lockdown. Hence, this study aims to identify level of depression, anxiety and stress among adult population of Nepal during covid-19 lockdown.

\section{METHODS}

A cross-section web based research design was used to assess level of depression, anxiety and stress among Nepalese residents during Covid-19 lockdown from July 11 to August 15, 2020. Residents of Nepal's selected provinces, aged 18 and over, who were willing to engage in the study and knew how to fill out the online form were included in the study. Health personnel were 
ISSN: 2362-1303 (Paper) | eISSN: 2362-1311 (Online)

excluded from the study. The study proceeded upon ethical clearance from Nepal Health Research Council (NHRC, Reg. No.492/2020) and taking informed consent from the respondents. Multistage sampling technique was used. Bagmati province, Gandaki Province and Lumbini province were selected by the lottery method. In the second step, three Districts were selected from every three Provinces (Kathmandu, Lalitpur, Chitwan) from province number 3,(Baglunj, Syangja, Kaski) from Gandaki province and Rupandehi, Palpa, Dang from province number 5. In the third step, proportionate stratified random sampling method was used to select total sample size of 422 Nepalese residents (Table 1). Finally, data was collected from participants by using emails and social media. The sample size was determined using the Cochran formula: $\mathrm{n}=\mathrm{Z} \alpha 2$ PQ $\mathrm{d} 2$ Where, $\mathrm{n}=$ sample size, Z=Reliability coefficient for the desired confidence interval $(\mathrm{CI})$ of $95 \%$. $\mathrm{P}=$ the prevalence of $=50 \% \mathrm{Q}=1-\mathrm{p} \mathrm{d}=\mathrm{degree}$ of precision $=0.05$ (probability of error). Confidence interval of $95 \%$, Margin of error $5 \% . \mathrm{n}=$ $(1.96) 2 \times 0.5 \times 0.5=0.9604=384(0.05) 20.0025$. By adding the $10 \%$ non-response rates to the sample size $=384+38=422$.

Data was collected by using the Nepali version of DASS 21 related to Depression, stress and anxiety level regarding COVID-19Lockdown among residents of Nepal. Informed consent was taken from each respondent after mentioning the objective of the study. Research questionnaire consisted of two parts; Part A: - Socio-demographic variables of the respondents and Part B: Identification of depression, anxiety and stress level of respondents which was measured by Depression, anxiety and Stress Subscales of DASS 21 tool. It consists of 21 statements with each scaling as 0,1,2 and 3.Total Scores was multiplied by 2 to calculate the final score.

Nepali version of DASS21 is already validated tool by Kareen N Tonsing (Tonsing, 2014).To assess the reliability of the DASS-21-N, Cronbach's alphas were computed for the three subscales. The internal consistency was 0.77 for DASS-D, 0.80 for DASS-A, and 0.82 for DASS-S which indicates good Cronbach's alpha values. 
ISSN: 2362-1303 (Paper) | eISSN: 2362-1311 (Online)

JOURNAL OF ADVANCED ACADEMIC RESEARCH (JAAR)

June 2021

Table 1: Sample Size from Each District

\begin{tabular}{|c|c|c|c|c|}
\hline $\mathbf{S N}$ & Province & District & $\begin{array}{l}\text { Total } \\
\text { Population } \\
\text { from } 18 \text { and } \\
\text { above } \\
\text { according to } \\
\text { census } 2011\end{array}$ & Sample \\
\hline 1 & $\begin{array}{l}\text { Province } \\
\text { number } 3 \\
\text { (Bagmati):, }\end{array}$ & Kathmandu, & $1,329,799$ & 143 \\
\hline 2 & Province 3 & Lalitpur & 356,023 & 38 \\
\hline 3 & Province 3 & Chitwan & 408,976 & 44 \\
\hline 4 & $\begin{array}{l}\text { Gandaki } \\
\text { Province }\end{array}$ & Baglunj & 171,841 & 19 \\
\hline 5 & $\begin{array}{l}\text { Gandaki } \\
\text { Province }\end{array}$ & Syangja & 194,696 & 21 \\
\hline 6 & $\begin{array}{l}\text { Gandaki } \\
\text { Province }\end{array}$ & Kaski & 349,893 & 38 \\
\hline 7 & Province 5 & Rupandehi & 580,688 & 63 \\
\hline 8 & Province 5 & Palpa & 171,212 & 18 \\
\hline 9 & Province 5 & Dang & 353,171 & 38 \\
\hline & & Total & $3,916,299$ & 422 \\
\hline
\end{tabular}


ISSN: 2362-1303 (Paper) | eISSN: 2362-1311 (Online)

JOURNAL OF ADVANCED ACADEMIC RESEARCH (JAAR)

June 2021

RESULTS

Table 2: Background Characteristics of the Respondents

\begin{tabular}{|c|c|c|}
\hline Characteristics & Number & Percent \\
\hline \multicolumn{3}{|l|}{ Age } \\
\hline $18-30$ & 233 & 55.2 \\
\hline $31-40$ & 126 & 29.9 \\
\hline $41-60$ & 62 & 14.7 \\
\hline 60 above & 1 & 0.2 \\
\hline \multicolumn{3}{|l|}{ Mean \pm SD $30.81 \pm 9.201$} \\
\hline \multicolumn{3}{|l|}{ Minimum age: 18} \\
\hline \multicolumn{3}{|l|}{ Maximum age: 62} \\
\hline \multicolumn{3}{|l|}{ Sex } \\
\hline Female & 200 & 47.4 \\
\hline Male & 222 & 52.6 \\
\hline \multicolumn{3}{|l|}{ Marital status } \\
\hline Unmarried & 181 & 42.9 \\
\hline Married & 237 & 56.2 \\
\hline Divorced & 1 & .2 \\
\hline Widowed & 3 & .7 \\
\hline \multicolumn{3}{|l|}{ Education level } \\
\hline Simple reading and writing & 5 & 1.2 \\
\hline Primary level & 7 & 1.7 \\
\hline Secondary & 38 & 9.0 \\
\hline Higher secondary & 92 & 21.8 \\
\hline University & 280 & 66.4 \\
\hline \multicolumn{3}{|l|}{ Occupation } \\
\hline Government & 59 & 14.0 \\
\hline Private & 111 & 26.3 \\
\hline Business & 68 & 16.1 \\
\hline Others & 184 & 43.6 \\
\hline
\end{tabular}

Table 2 shows that out of 422 respondents, 236 (55.9\%) were from the age group 18-30 years with mean age Mean \pm SD 30.81 \pm 9.201 years ranging from 18 to 62 years, 222(52.6\%) were males. Likewise, more than half of the respondents $237(56.2 \%)$ were married, 280(66.4\%) had university level of education. 
ISSN: 2362-1303 (Paper) | eISSN: 2362-1311 (Online)

JOURNAL OF ADVANCED ACADEMIC RESEARCH (JAAR)

June 2021

Table 3: Level of Depression, Stress and Anxiety among Nepalese Residents during Covid19 Lockdown

\begin{tabular}{ccccccc}
\hline Level & \multicolumn{2}{c}{ Depression } & \multicolumn{2}{c}{ Anxiety } & \multicolumn{2}{c}{ Stress } \\
& $\mathbf{N}$ & $\mathbf{\%}$ & $\mathbf{N}$ & $\mathbf{\%}$ & $\mathbf{N}$ & $\%$ \\
\hline Normal & 274 & 64.9 & 291 & 69 & 327 & 77.5 \\
Mild & 54 & 13.7 & 26 & 6.2 & 36 & 8.5 \\
Moderate & 61 & 14.5 & 64 & 15.2 & 32 & 7.6 \\
Severe & 18 & 4.3 & 16 & 3.8 & 22 & 5.2 \\
Extremely severe & 11 & 2.6 & 25 & 5.9 & 5 & 1.2 \\
\hline
\end{tabular}

Regarding level of depression, stress and anxiety most of the respondents 327(77.5\%) did not have any stress. Likewise more than half of the respondents 291(69\%) did not have any anxiety and $274(64.9 \%)$ did not have any depression. Similarly, 64 (15.2\%) of respondents had moderate level of anxiety, followed by 61(14.5\%) who had moderate level of depression and $54(13.7 \%)$ had mild level of depression. Regarding extremely severe levels, only 11(6.2\%) were depressed, 25(5.9\%) had anxiety and 5(1.2\%) were stressed (Table 3). 
ISSN: 2362-1303 (Paper) | eISSN: 2362-1311 (Online)

JOURNAL OF ADVANCED ACADEMIC RESEARCH (JAAR)

June 2021

Table 4: Difference of Socio Demographic variables with the level of Depression, Stress and Anxiety among Nepalese residents.

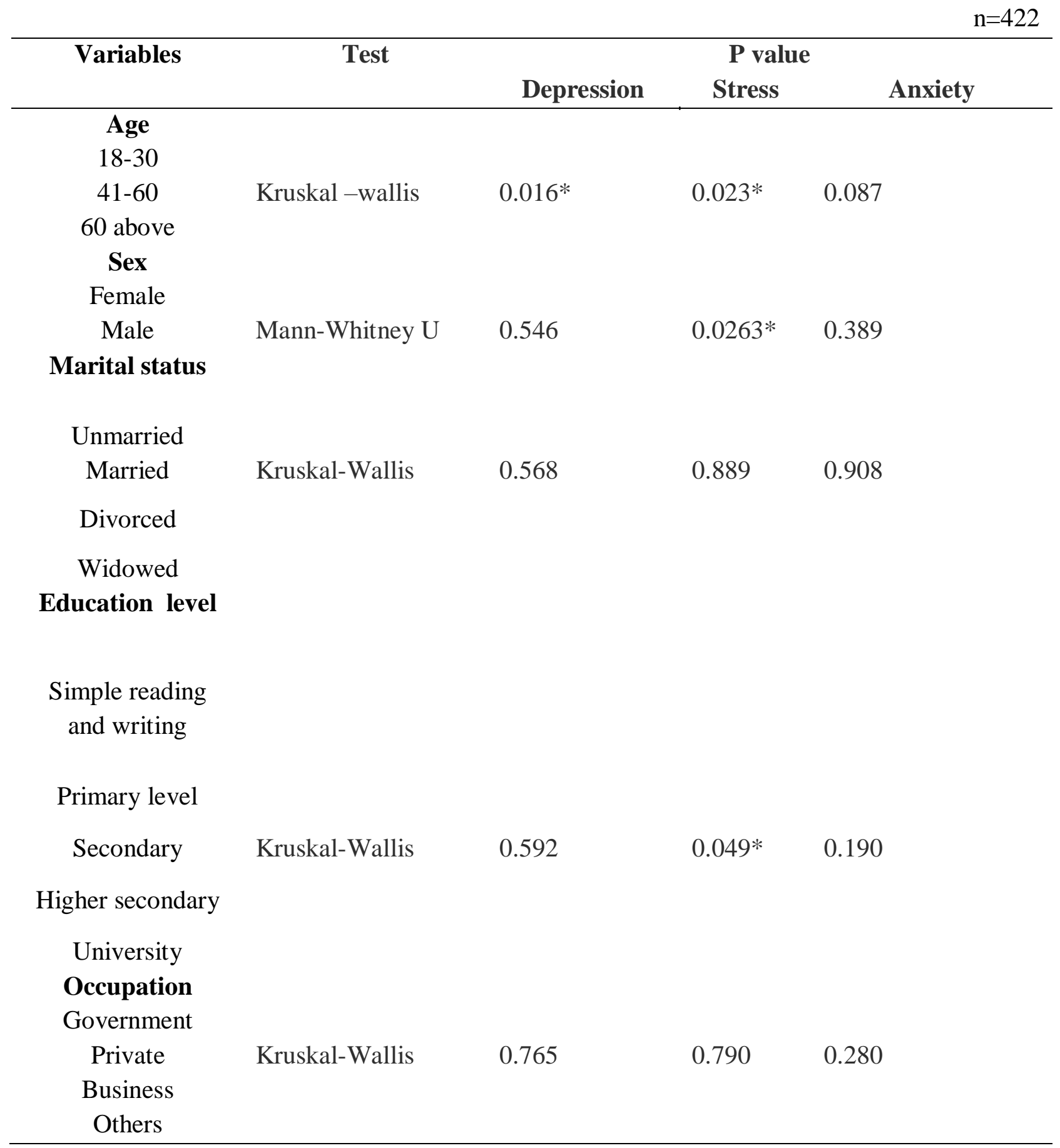

Note: $* \mathrm{p}<0.05$ significant at $95 \%$ confidence level 
Table 4 shows that there was significant difference between depression and age $(\mathrm{P}=0.016)$, depression and $\operatorname{sex}(\mathrm{p}=0.023)$ at a $95 \%$ level of significance. Also there was significant difference between stress and age $(\mathrm{p}=0.023)$, sex $(\mathrm{p}=0.0263)$ and education level $(\mathrm{p}=0.049)$.

\section{DISCUSSION}

Aims of this study were to identify level of depression, stress and anxiety during lockdown and their differences with socio-demographic characteristics among Nepalese residents. Nepali version of DASS 21 was used to identify Depression, stress and anxiety level. The lockdown is bound to have mental health impacts on an individual. In this study, most of the respondents (77.5\%) did not have any stress, (69\%) did not have any anxiety and (64.9\%) did not have any depression. Only $15.2 \%$ of respondents had moderate level of anxiety, followed by $14.5 \%$ with moderate level of depression and $13.7 \%$ with mild level of depression. Regarding extremely severe levels, only (6.2\%) were depressed, (5.9\%) had anxiety and (1.2\%) were stressed. Though fear seems to be certain as an effect of mass quarantine and anxiety is most likely to escalate, the results of this study do not reflect remarkable level of depression, stress and anxiety. In another study conducted in Nepal, similar results were seen where only $11 \%$ were in mild to moderate stress, and $0.5 \%$ were in severe stress. Stress was more common in people over 45 years old, females, and those with a post-secondary education. Similarly, in this study there was significant difference between depression with age and sex. Also there was significant difference between stress with age, sex and education level (Shrestha et.al., 2020). A study carried out in India almost a quarter of the participants (25.1\%) were depressed, 99 (28\%) were anxious, and 41 $(11.6 \%)$ were stressed, which is similar to the findings of this study. Employed status was associated with depression and anxiety. This could be due to the loss of hundreds of thousands of jobs around the world. (Verma \& Mishra, 2020). Unlikely to it, occupation did not have any effect on the results of this study, where majority were involved in private jobs which were most probably shut down during lockdown. Similar results were found in a study conducted in Saudi Arabia, where almost half of the respondents were at normal level of depression (44.9\%), anxiety (35.6\%) and stress (55\%). Also, depression did correlate with age. One possible explanation, according to an author, is that the epidemic had not yet peaked at the time of the study, and the number of reported cases in the study settings was very low. This study's outcome could have been influenced by a similar reason. (Saleh et.al ., 2020). Similar results were found in another study conducted in India where the respondents suffered from mild to moderate level of anxiety and depression. Contrary to the findings of this study, males and females did not differ significantly on anxiety or depression (Rehman et.al., 2020). In a study of young individuals from six different countries, depression, anxiety, and stress were shown to be prevalent in $57 \%$, $40.5 \%$, and $38.1 \%$, respectively. (Al Omarioet.al., 2020). This result is contradictory to this research. 
ISSN: 2362-1303 (Paper) | eISSN: 2362-1311 (Online)

JOURNAL OF ADVANCED ACADEMIC RESEARCH (JAAR)

June 2021

\section{CONCLUSIONS}

The study concluded that more than half of the respondents were normal during the study period. However, the result followed by moderately depressed and anxious respondents during Covid-19 lockdown where young adults were more psychologically affected than older adults. Likewise, male were more affected than female. Hence, this study emphasizes conducting more in-depth studies regarding mental health consequences and also aftermath post-traumatic consequences of Covid-19 pandemic.

\section{ACKNOWLEDGEMENTS}

We are thankful to the Nepal health Research Council for supporting us to conduct this study. We also express our sincere gratitude to all the respondents of the study.

\section{Received: 9 May 2021}

Accepted: 23 June 2021

Published: 28 June 2021

\section{REFRENCES}

Al Omari, O., Al Sabei, S., Al Rawajfah, O., Abu Sharour, L., Aljohani, K., Alomari, K., Shkman, L., Al Dameery, K., Saifan, A., Al Zubidi, B., Anwar, S., \& Alhalaiqa, F. (2020). Prevalence and Predictors of Depression, Anxiety, and Stress among Youth at the Time of COVID-19: An Online Cross-Sectional Multicountry Study. Depression Research and Treatment, 2020, 1-9. https://doi.org/10.1155/2020/8887727

Asmundson, G. J., \& Taylor, S. (2020). Coronaphobia: Fear and the 2019-nCoV outbreak. Journal of Anxiety Disorders, 70, 102196. https://doi.org/10.1016/j.janxdis.2020.102196

Bhat, B., Khan, S., Manzoo, S., Niyaz, A., Tak, H., \& Anees, S. (2020). A Study on Impact of COVID-19 Lockdown on Psychological Health, Economy and Social Life of People in Kashmir.International Journal of Science and Healthcare Research, 5(2), 36-46.

Brooks, S. K., Webster, R. K., Smith, L. E., Woodland, L., Wessely, S., Greenberg, N., \& Rubin, G. J. (2020). The psychological impact of quarantine and how to reduce it: rapid review of the evidence. The Lancet, 395(10227), 912-920. https://doi.org/10.1016/s01406736(20)30460-8

COVID-19 pandemic in Nepal. (2020). United Nations Development Program. https://www.np.undp.org/content/nepal/en/home/coronavirus.html

Dong, L., \&Bouey, J. (2020).Public Mental Health Crisis during COVID-19 Pandemic, China.Emerging Infectious Diseases, 26(7), 1616-1618. https://doi.org/10.3201/eid2607.200407 
ISSN: 2362-1303 (Paper) | eISSN: 2362-1311 (Online)

Frequently Asked Questions about coronavirus disease (COVID-19).(n.d.). The United Nations Internation Children's Education Fund. https://www.unicef.org/indonesia/coronavirus/FAQ\#whatiscoronavirus

Rajkumar, R. P. (2020). COVID-19 and mental health: A review of the existing literature. Asian Journal of Psychiatry, 52, 102066.https://doi.org/10.1016/j.ajp.2020.102066

Rehman, U., Shahnawaz, M. G., Khan, N. H., Kharshiing, K. D., Khursheed, M., Gupta, K., Kashyap, D., \&Uniyal, R. (2020). Depression, Anxiety and Stress Among Indians in Times of Covid-19 Lockdown. Community Mental Health Journal, 57(1), 42-48. https://doi.org/10.1007/s10597-020-00664-X

Saleh, K. A., Nasser, H. A., Harabah, K. A., Orefan, Z. A., \&Mousa, O. (2020). Assessing depression, anxiety, stress and associated factors during COVID-19 lockdown among adult population in Al Ahsa, Saudi Arabia. International Journal of Advances in Medicine, 8(1), 34. https://doi.org/10.18203/2349-3933.ijam20205467

Shrestha, D. B., Thapa, B. B., Katuwal, N., Shrestha, B., Pant, C., Basnet, B., Mandal, P., Gurung, A., Agrawal, A., \&Rouniyar, R. (2020). Psychological distress in Nepalese residents during COVID-19 pandemic: a community level survey. BMC Psychiatry, 20(1). https://doi.org/10.1186/s12888-020-02904-6

Suicide cases on the rise, mental health experts warn of a 'grim situation. '(n.d.).My Republica. https://myrepublica.nagariknetwork.com/news/suicide-cases-on-the-rise-mental-healthexperts-warn-of-a-grim-situation/

Tonsing, K. N. (2014). Psychometric properties and validation of Nepali version of the Depression Anxiety Stress Scales (DASS-21). Asian Journal of Psychiatry, 8, 63-66. https://doi.org/10.1016/j.ajp.2013.11.001

Verma, S., \& Mishra, A. (2020).Depression, anxiety, and stress and socio-demographic correlates among general Indian public during COVID-19.International Journal of Social Psychiatry, 66(8), 756-762. https://doi.org/10.1177/0020764020934508

Working together to prevent suicide among children and young people in Nepal. (2020, September 10). UNICEF Nepal. https://www.unicef.org/nepal/press-releases/workingtogether-prevent-suicide-among-children-and-young-people-nepal 